\title{
Histoplasmosis oral localizada: Reporte de un caso clínico en Tucumán, Argentina
}

\author{
ALICIA WIERNA ${ }^{\text {la }}$, ANA ANSONNAUD ${ }^{\text {la }}$, \\ ANALÍA SORIA $^{2 b}$, MAURICIO GONZÁLEZ Mc D. ${ }^{1 \mathrm{a}}$ \\ Localized oral histoplasmosis. \\ Report of one case
}

Histoplasmosis is an endemic deep mycosis produced by Histoplasma capsulatum, a dimorphic fungus. It penetrates into the organism by inhalation and spreads by lymphatic or hematic route. We report a 57-year-old immunocompetent male presenting with an enlargement of the tongue that also exhibited white pseudomembranes. There were also nodular lesions in the dorsum of the tongue, separated by deep grooves. The pathological study revealed a chronic inflammatory process with granulomas. The microbiological examination with the Giemsa technique showed multiple yeasts of 4-5 mm of diameter with a clear halo inside macrophages and epithelial cells, compatible with the parasitic phase of Histoplasma capsulatum. Serology was positive for the histoplasmine antigen. The patient was treated with Itraconazole 200 $\mathrm{mg} /$ day, experiencing $40 \%$ remission of lesions during the first month of treatment.

(Rev Med Chile 2010; 138: 586-589).

Key words: Histoplasma; Itraconazole; Mycoses.

L a histoplasmosis clásica es una micosis profunda producida por un hongo dimorfo, el Histoplasma capsulatum. Las zonas endémicas se presentan en América del Norte, Central y América del Sur, Malasia e Indonesia ${ }^{1}$. En Argentina se presentaron casos en la Pampa húmeda, zona noroeste y en el Gran Buenos Aires $^{2}$. La infección se produce por inhalación de polvo contaminado con las microconidias de la forma micelial del hongo, alcanzando los macrófagos alveolares donde se transforma en levaduras. Clínicamente se puede presentar en tres formas: como una infección pulmonar aguda que puede cursar sin síntomas o puede producir síntomas semejantes al virus de la influenza; una forma pulmonar crónica que presenta síntomas semejantes a la tuberculosis y una forma diseminada que ocurre en niños, ancianos, pacientes inmunocomprometidos caracterizada por diseminación progresiva en sitios extra pulmonares ${ }^{3}$. La incidencia de manifestaciones orales tiene importancia en pacientes con $\mathrm{SIDA}^{4}$, siendo pocos los casos descriptos en individuos inmunocompetentes ${ }^{5,6}$. Se presenta un caso de histoplasmosis en un paciente de sexo masculino VIH negativo, con manifestaciones exclusivas en la cavidad bucal.

\section{Caso clínico}

Paciente de sexo masculino de 57 años de edad, procedente de la ciudad de San Miguel de Tucumán, provincia de Tucumán. Se presentó a la consulta por lesiones en su lengua con 7 meses de antigüedad. Era fumador de 10 cigarrillos diarios. El examen neurológico fue normal. Los resultados obtenidos de los exámenes bioquímicos (hemograma completo, eritrosedimentación, glicemia, ácido úrico, alanino-aminotransferasa (ALT) y aspartato-aminotransferasa (AST) estaban dentro de los parámetros normales. La serología para el VIH y la prueba de tuberculina (PPD) fueron negativas. La radiografía del tórax y la resonancia magnética del cuello fueron normales. En el examen intraoral 


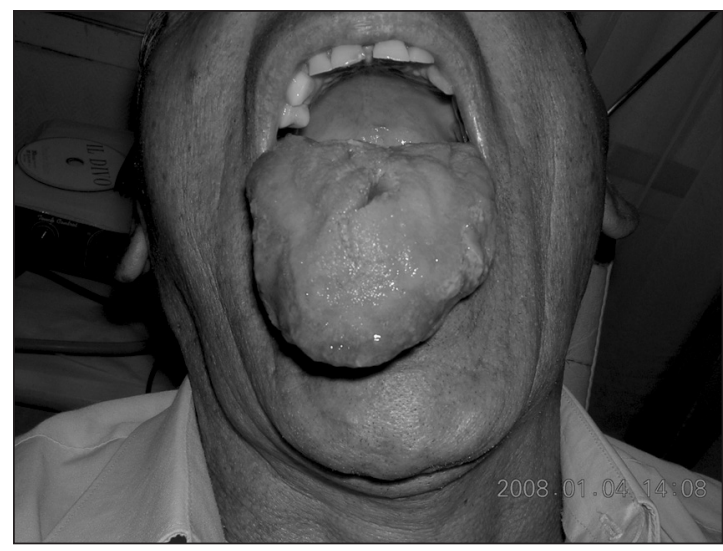

Figura 1. Vista frontal: Macroglosia asimétrica, con lesiones nodulares y fisuras en su dorso, y erosiones en sus bordes.

se comprobó que era un paciente parcialmente dentado y que los elementos remanentes presentaban una marcada atricción consecuencia de su bruxomanía. Al examinar la lengua se comprobó un marcado aumento del volumen, con lesiones erosivas y sangrantes tanto en la punta como en los bordes que estaban en íntimo contacto con los elementos remanentes (Figura 1). Dichas lesiones fueron consecuencia del aumento del volumen de la lengua que presionaba contra los bordes filosos de dichos elementos, razón por la cual se le realizó un desgaste y pulido de los elementos. Asimismo, la lengua presentaba pseudomembranas blanquecinas que no se desprendían al pasar una gasa. El dorso lingual presentaba lesiones tipo nodulares separadas en algunos sectores por profundos surcos. En una vista lateral derecha e izquierda se evidenció el aumento del volumen lingual en su mitad anterior (Figura 2). Al palpar dorso se pudo comprobar aumento de la consistencia (tipo acartonada), reconociendo perfectamente formaciones en apariencia subcoriónicas hemisféricas, dicha maniobra no evidenció dolor en la zona. La palpación de vientre lingual y piso de boca no reveló alteraciones en la consistencia. A nivel submaxilar no se evidenció adenopatías. Se tomó muestra del borde lingual que se envió para examen histopatológico y microbiológico. La histopatología demostró un tejido con lesión granulomatosa, células plasmáticas y gigantes, exudación y úlceras asociadas. El examen microbiológico dio negativo. Dos semanas después se le realizó una nueva toma de biopsia, esta vez de las

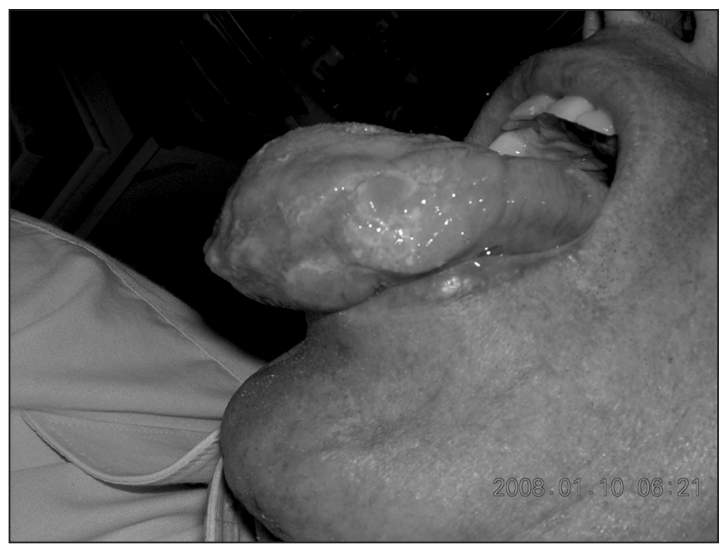

Figura 2. Vista lateral: Marcado aumento de volumen en su mitad anterior, con evidentes formaciones nodulares comprometiendo el espesor en su totalidad.

lesiones nodulares del dorso lingual, revelando este estudio un microgranuloma con células gigantes multinucleadas (tipo Langhans), sin necrosis central. No se identificó el agente causal. El paciente regresó a la consulta ocho meses después. Al examen se observó que la lengua duplicó su volumen con aspecto de dos lenguas apiladas, presentando dificultad en la dicción. La palpación puso de manifiesto una disminución de la dureza del dorso lingual, pero aumentó en su cara ventral. No se comprobó compromiso del piso de la boca pero presentaba adenopatías submaxilares ligeramente dolorosas. Se solicitó examen microbiológico del material obtenido La coloración con la técnica de Giemsa permitió la visualización de múltiples levaduras de 4-5 mm de diámetro con un halo claro dentro de los macrófagos y células epiteliales compatible con la fase parasitaria del Histoplasma capsulatum. Las coloraciones de Gram para Actynomices, de Kinyoun para Norcardia, y el montaje en tinta china para criptococo fueron negativas. La serología, empleando inmunoelectroforesis y contrainmunoelectroforesis fue positiva para el antígeno histoplasmina. Estos hallazgos y la ausencia de manifestaciones sistémicas u otras manifestaciones conducen al diagnóstico de histoplasmosis oral localizada. Se lo derivó a un servicio público de Infectología, para su tratamiento con itraconazol $200 \mathrm{mg}$ /día con una regresión de 40\% de la lesión durante el primer mes de tratamiento. Como secuelas cicatriciales, presentó bridas fibrosas en la cara ventral, tanto en su lado derecho como izquierdo. 


\section{Discusión}

El Histoplasma capsulatum se encuentra presente como conidios en suelos ricos en nitrógeno, por la presencia de guano de murciélagos y pájaros: cuevas, minas, gallineros, etc. En Argentina se comunicó el primer aislamiento del Histoplasma capsulatum var. capsulatum en un murciélago macho de la especie Eumops Bonariensis, siendo el primer registro en el mundo de que este mamífero actúe como reservorio y disperse el hongo en la naturaleza ${ }^{7}$. Los conidios penetran al organismo por vía respiratoria, razón por la cual los pulmones están comprometidos en la mayoría de los casos. La temperatura y humedad corporal permiten su transformación a levadura, que es el fenotipo patógeno capaz de multiplicarse y estimular a los linfocitos T (CD4+) (producción de citoquinas principalmente IFN- $\gamma$ y TNF- $\alpha$ ) que activan a los macrófagos y producen granulomas epitelioides que tienden a controlar la infección, curando espontáneamente en la mayoría de las personas ${ }^{8}$. En un individuo inmunocompetente, las levaduras pueden permanecer por años en el interior de los macrófagos, sin manifestarse como enfermedad propiamente dicha. La histoplasmosis es una infección oportunista común en pacientes infectados con VIH quienes residen en áreas endémicas, en pacientes con neoplasias linforeticular y aquellos que reciben corticoides, terapia citotóxica y agentes inmunosupresivos, los que están predispuestos a padecer histoplasmosis diseminada. En los casos crónicos las lesiones mucosas son las más frecuentes. En los casos agudos y subagudos suele observarse en niños de la primera infancia y en pacientes con falla grave de la inmunidad mediada por células, como enfermos VIH positivos, presentándose en este último caso como pequeñas pápulas cutáneas con el vértice ulcerado, y en los receptores de trasplantes de órganos como nódulos eritematosos que evolucionan a la necrosis ${ }^{9,10}$. Valle et al reportan un caso raro de histoplasmosis crónica diseminada con lesiones ulceradas de la cavidad oral sin signos o síntomas sistémicos en un paciente alcohólico, VIH negativo en Brasil. El análisis histopatológico reveló un proceso inflamatorio crónico con granulomas conteniendo organismos fúngicos ${ }^{11}$. Recientemente se documentaron otros casos de histoplasmosis crónica diseminada, en Argentina, uno en una paciente con artritis reumatoidea, VIH negativa, la que consultó por úlcera en la lengua como única manifestación. La histopatología fue compatible y el cultivo positivo para Histoplasma capsulatum ${ }^{12}$ y otro en un paciente que se encontraba en tratamiento por una neumopatía diagnosticada como tuberculosis (TBC) con una masa tumoral ulcerada localizada en el reborde residual inferior en la zona de 31,32 y 33 , extendiéndose hacia el fondo de surco vestibular y al piso de la boca, cuyo diagnóstico histopatológico fue lesión crónica granulomatosa ulcerada por Histoplasma capsulatum $^{13}$. El reconocimiento de pacientes con histoplasmosis mucocutáneas en pacientes inmunocompetentes sin enfermedad sistémica detectable es controvertido. Algunos autores sugieren que la manifestación inicial de localización oral posteriormente evolucionará con manifestaciones clínicas en otros órganos ${ }^{14}$. Sin embargo, desde 1946 se documentan casos de histoplasmosis mucocutáneas primaria en pacientes inmunocompetentes ${ }^{15,16}$. El caso clínico presentado corresponde a un individuo que vive en un área endémica y que por sus actividades laborales se encontraba expuesto. El paciente asistió a la consulta por una lesión en la cavidad oral, llevaba siete meses asistido por distintos profesionales de la salud sin arribar a un diagnóstico de certeza. Por el cuadro clínico, imagen histológica y ausencia de microorganismos en el primer estudio microscópico se pensó en una TBC, una sarcoidosis o en una micosis profunda con localización exclusiva lingual, ya que no presentaba compromiso pulmonar, ni ganglionar. No presentó ninguna causa por la cual se podría sospechar un estado inmunológico deprimido. La presencia de lesión granulomatosa e inflamatoria podría indicar una buena respuesta inmunológica del paciente. El tratamiento que recibe el paciente corresponde al de histoplasmosis oral, como una enfermedad localizada, el cual es menos tóxico que la terapia que se aplica en pacientes con enfermedad diseminada. Es importante destacar el desempeño que cumple el odontólogo en el diagnóstico de lesiones orales cuyo agente etiológico es el Histoplasma capsulatum; el profesional debe tener presente que si bien es frecuente que esta patología se presente en pacientes inmunocomprometidos, se puede presentar también en pacientes inmunocompetentes. Asimismo, se debe establecer la pronta relación con el médico infectólogo para realizar el tratamiento específico oportuno lo cual reduce la 
morbi-mortalidad en estos pacientes. A pesar que Chile no es zona endémica, los profesionales de la salud deben tener en cuenta la gran afluencia de argentinos a ese país, para residir en forma transitoria o permanente, por lo que creemos importante considerar en el diagnóstico diferencial esta patología.

\section{Referencias}

1. Boutros HH, Van Winckle RB, Evans GA, Wasan SM, Oral histoplasmosis masquerading as an invasive carcinoma. Journal of Oral and Maxillofacial Surgery 1995; 53: 1110-14.

2. Negroni-Briz R. Histoplasmosis. En: Torres-Rodríguez J, del Palacio-Hernanz A, Guarro-Artigas J, Negroni-Briz R, Pereiro Miguens M. Micología médica. Barcelona: Masson SA; 1993. p. 247-56.

3. Wheat LJ. Laboratory diagnosis of histoplasmosis: update 2000. Seminars in Respiratory Infections 2001; 16: 131-40.

4. Trombetta L, Bava AJ. Laboratorio clínico y micológico en pacientes con histoplasmosis y síndrome de inmunodeficiencia adquirida. Acta Bioquím. Clín Latinoam 2005; 39: 471-6.

5. Padhye AA, Pathak AA, Katkae VJ, Hazare VK, Kaufman L. Oral histoplasmosis in India: a case report and an overview of cases reported during 1968-1992. Journal of Medical and Veterinary Mycology 1994; 32: 93-103.

6. Thiago P de T, dos Santos JI, Steindel M: Histoplasmosis in the region of the hard palate simulating a lesion caused by leishmania. Revista da Sociedade Brasileira de Medicina Tropical 1998; 31: 225-9.

7. Canteros CE, Iachini RH, Rivas MC, Vaccaro O, Ma- dariaga J, Galarza R, et al. Primer aislamiento de Histoplasma capsulatum de murciélago urbano Eumops bonariensis. Rev Argent Microbiol 2005; 37: 46-56.

8. Nosanchuk JD, Gacser A. Histoplasma capsulatum at the host pathogen interface. Microbes and Infection 2008; 10: 973-7.

9. Laniado-Laborín R. Coccidioidomycosis and other endemic mycoses in Mexico Rev Iberoam Micol 2007; 24: 249-58.

10. Negroni R. Manifestaciones cutáneo-mucosas de la histoplasmosis diseminada (histoplasmosis clásica o histoplasmosis capsulati). Dermatol Argent 2008; 14: 104-112.

11. Valle do ACF, Moreira LC, Almeida-Paes R, Moreira JS, Pizzini CV, Muniz M, et al. Chronic disseminated histoplasmosis with lesions restricted to the mouth: case report. Rev Inst Med trop S Paulo 2006; 48: 113-6.

12. Carbó Amoroso EJ, Díaz MG, Federico D, Guardati MV, Reyes MA, Weidmann J, et al. Úlcera de lengua como presentación del Histoplasma capsulatum. Rev Argent Dermatol 2008; 89: 112-8.

13. Dorati P, Baudo JE, Casariego Z. Histoplasmosis Diseminada: caso clínico. RAOA 2006; 95: 133-5.

14. Young LL, Dolan CT, Sheridan PJ, Reeve CM. Oral manifestations of histoplasmosis. Oral Surgery 1972; 33: 191-204.

15. Leal Alcure M, Di Hipólito O, Paes de Almeida O, Bonilha H, Lopes MA. Histoplasmosis in an HIV-negative patient. Oral Surg Oral Med Oral Pathol Oral Radiol Endod 2006; 101: E33-6.

16. Mignogna MD, Fedele S, Lo Russo L, Ruoppo E, Lo Muzio L. A case of oral localized histoplasmosis in an immunocompetent patient. Eur J Clin Microbiol Infect Dis 2001; 20: 753-5. 